MISS KATRIEN VANDEPITTE (Orcid ID : 0000-0003-1031-8728)

Received Date : 30-Nov-2015

Revised Date : 23-Feb-2017

Accepted Date : 09-Mar-2017

Article type : Original Article

\title{
Retention of gene diversity during the spread of a non-native plant species
}

Authors: Katrien Vandepitte ${ }^{\mathrm{a}}$, Kenny Helsen ${ }^{\mathrm{a}}$, Kasper Van Acker ${ }^{\mathrm{a}}$, Joachim Mergeay ${ }^{\mathrm{b}}$, Olivier Honnay ${ }^{\mathrm{a}}$

a Plant Conservation and Population Biology, Biology Department, University of Leuven, Kasteelpark Arenberg 31, B-3001 Heverlee, Belgium.

${ }^{\mathrm{b}}$ Research Institute for Nature and Forest, Gaverstraat 4, B-9500 Geraardsbergen, Belgium

Corresponding author: Katrien Vandepitte

Address: Plant Conservation and Population Biology, Biology Department, University of Leuven, Kasteelpark Arenberg 31, B-3001 Heverlee, Belgium.

E-mail: katrien.vandepitte@bio.kuleuven.be

Running title: The population genomics of spreading neobiota

Word count: 4267

This article has been accepted for publication and undergone full peer review but has not been through the copyediting, typesetting, pagination and proofreading process, which may lead to differences between this version and the Version of Record. Please cite this article as doi:

$10.1111 / \mathrm{mec} .14119$

This article is protected by copyright. All rights reserved. 


\section{Abstract}

Spatial expansion, which is a crucial stage in the process to successful biological invasion, is anticipated to profoundly affect the magnitude and spatial distribution of genetic diversity in novel colonized areas. Here we show that, contrasting common expectations, Pyrenean rocket (Sisymbrium austriacum), retained SNP diversity as this introduced plant species descended in the Meuse river basin. Allele frequencies did not mirror between-population distances along the predominant expansion axis. Reconstruction of invasion history based on the genotypes of historical herbarium specimens indicated no influence of additional introductions or multiple points of entry on this nongradual pattern. Assignment analysis suggested the admixture of distant upstream sources in recently founded downstream populations. River dynamics seem to have facilitated occasional long distance dispersal which brought diversity to the expansion front and, so maintained evolutionary potential. Our findings highlight the merit of a historical framework in interpreting extant patterns of genetic diversity in introduced species and underscore the need to integrate long distance dispersal events in theoretical work on the genetic consequences of range expansion.

Keywords: SNP, non-native plant, spatial expansion, genic diversity, population genetic, reconstruction, introduction history, herbarium specimen

\section{Introduction}

Spatial expansion, which is a crucial stage in the process to successful biological invasion, is anticipated to profoundly affect the magnitude and spatial distribution of intraspecific diversity in novel colonized areas (Excoffier et al. 2009). This is because genetic drift at the expansion front can increase at each subsequent founding event, leading to serial founder effects (Le Corre \& Kremer 1998, Slatkin \& Excoffier 2012). The spatial spread of successfully introduced and established

This article is protected by copyright. All rights reserved. 
neobiota can therefore be expected to result in strong genetic clines, to progressively reduce mean within-population genetic diversity along the expansion axis, and to promote the fixation of mostly deleterious alleles towards the expansion front ('allele surfing'; Hallatschek \& Nelson 2008, Slatkin \& Excoffier 2012, Peischl et al. 2013, Peischl \& Excoffier 2015). This can be expected to inflate genetic load at the expanding range margin ('expansion load') and eventually deplete adaptive potential, which seems to contradict the massive proliferation of some introduced species.

Yet, where theory on the evolutionary genetic consequences of spatial expansion is extensive, empirical data, certainly with regard to spreading non-native species, are far more scant. Population genetic research has thus far dealt primarily with the influence of genetic bottlenecks and founder diversity during the initial introduction (reviewed in Dlugosch \& Parker 2008), while the influence of subsequent spatial expansion has largely been ignored (but see e.g. Bronnenhuber et al. 2011, Berthouly-Salazar et al. 2013, White et al. 2013). More importantly, and in addition to serial founder effects, also additional introductions after initial establishment, gene flow among populations from different points of entry, and rapid local adaptation may influence the development of population genetic structure in spreading neobiota (Rosenthal et al. 2008, Lachmuth et al. 2010, Bronnenhuber et al. 2011). Invasion histories are however typically difficult to reconstruct with confidence, certainly when historical information is poor and genetic data of the initial stages of the invasion process are not available (Möst et al. 2015). As a consequence, we still know relatively little of the processes shaping the spatial distribution of genetic diversity in spreading neobiota.

Here, we investigated the influence of the introduction and spread of the herbaceous plant species Sisymbrium austriacum subsp. chrysanthum (Rouy et Fouc) in the Meuse river basin (Belgium and The Netherlands) on the development of population genetic structure. This diploid ( $2 n=14 x)$ member of the Brassicacea family is native to the mountainous regions in the south of France and the north of Spain (mainly the Pyrenees; Tutin 1983). The species' self-compatible flowers are pollinated by insects (bees and syrphid flies). In Belgium, Pyrenean rocket was first recorded by A.S.L. Lejeune, who

This article is protected by copyright. All rights reserved. 
surveyed the Vesdre, a tributary to the Meuse, during the early $19^{\text {th }}$ century (Van Landuyt et al. 2006). S. austriacum most likely hitched along with massive wool transport from Southwest Europe to the wool industry area near the city of Verviers (Verloove 2006), upstream the river Vesdre during the $18^{\text {th }}$ or early $19^{\text {th }}$ century (area near the most upstream existent introduced populations $\ln 1$ and In2 in Fig. 1). Prior to processing, wool was washed in the river Vesdre and tributary canals near the city of Verviers, which likely provided plenty of opportunities for the introduction of light and tiny $S$. austriacum seeds contaminating the wool. From there on, the species probably colonized river borders in the valleys of the Meuse basin in downstream direction. Introduced populations outside of the Meuse river basin are very rare and most likely hitchhiked along with sand or gravel excavations for building purposes. Seeds dispersal over longer distances seems primarily facilitated by water, possibly through the downstream movement of fruiting branches, as highlighted by a previous genetic assignment analysis based on AFLP markers across a short transect along the Meuse (area between $\ln 10$ and $\ln 12$ in Fig. 1; Jacquemyn et al. 2010).

We previously developed a panel of single nucleotide polymorphisms (SNPs) to screen annotated sequence variation (Vandepitte et al. 2013), which we recently employed to identify the genomic signature of selection between the introduced and native ranges by analyzing gene functions and temporal changes in the most divergent 'outlier' SNPs (Vandepitte et al. 2014). In the present study, we focus on the processes shaping the genome-wide magnitude and spatial distribution of extant genetic diversity in the new range. We first infer the introduction history by comparing genotypes of historical herbarium specimens collected in the introduced range (Vesdre and Meuse) between 1830 and 1955 with extant native and introduced populations. We then explore the current spatial distribution of genetic variation in the introduced range. Finally, we evaluate the genetic consequences of spatial expansion, hypothesizing that serial founder effects and allele surfing would lead to strong genetic clines, progressive loss of gene diversity and the fixation of alleles with increasing distances along the river course from the site of initial colonization.

This article is protected by copyright. All rights reserved. 


\section{Materials and methods}

\section{Data generation}

Individuals were collected and genotyped as previously described in Vandepitte et al. (2014). In short, populations were identified during several field surveys in the Meuse river basin and the Pyrenees in 2009 and 2010. Leaf samples were collected from 11 native and 12 introduced populations spanning the species geographic range. All populations identified along the river Vesdre (In1 to In8 in Fig. 1) consisting of more than 10 individuals were sampled, in addition to four randomly chosen populations along the river Meuse ( $\ln 9$ to $\ln 12)$, where the species is more abundant. The three most downstream located Meuse populations are most likely founded after 1980 (In10 to In12 in Fig. 1; Jacquemyn et al. 2006, 2010). We did not observe the study species upstream of In1 on the Vesdre river (Fig. 1; personal observation K. Van Acker), nor upstream of the intersection of Vesdre and Meuse. Some established populations occur downstream of $\ln 12$ along the Meuse river (Fig. 1; personal observation K. Vandepitte). We sampled all individuals of populations smaller than 20 individuals, and 20 to 25 individuals in larger populations for genotyping (Table 1). Leaf material of 50 dated and two undated historical specimens collected by Barthélemy $\mathrm{CJ}$ Dumortier ( $\left.{ }^{\circ} 1797-1878\right)$ was obtained from the herbaria of the National Botanic Garden of Belgium and the University of Liège (for more details on the extant and historical individuals collected see Vandepitte et al. 2014).

DNA was extracted using the Nucleospin DNA-extraction kit (Macherey Nhagel, Germany). To increase the yield of DNA extracted from herbarium specimens the cell lysis phase was extended to $16 \mathrm{~h}$ at $65^{\circ} \mathrm{C}$. Aerosol resistant pipet tips were used to eliminate cross contamination and ten negative (water) controls were ran along with the samples. Individuals were genotyped on 243 SNPs, previously developed from Paired End RAD (Restriction site associated DNA) sequences, using KASPar technology (Genotyping by Allele-Specific Amplification; Cuppen 2007) as detailed in Vandepitte et al. (2013).

This article is protected by copyright. All rights reserved. 


\section{Data trimming}

SNPs and individuals with excess missing calls ( $>10 \%$ for SNPs and $>20 \%$ for individuals) were removed. Analysis of linkage disequilibrium in POPGENE 1.32 (Yeh et al. 1999) showed that none of the remaining SNP pairs were significantly linked across all populations (all $P>0.01$ ), as a result of which 206 SNPs were retained in 198 native, 47 historical and 188 current introduced individuals (433 out of 437 attempted individuals). Next, to assure selective neutrality in our dataset, we performed an $\mathrm{F}_{\mathrm{ST}}$ outlier analysis, using the simulation method of Beaumont \& Nichols (1996) extended to the case of a hierarchical population structure in ARLEQUIN version 3.5 (Excoffier \& Lischer 2010). Null distributions were generated based on all extant native and introduced individuals applying $1 \times 10^{5}$ simulations across SNPs. All 26 SNPs exceeding the $99 \%$ upper or lower $F_{\text {ST }}$ confidence intervals were excluded from further analyses. Most positive outlier SNPs were divergent between the two ranges as previously discussed in Vandepitte et al. (2014).

\section{Data analysis}

\section{Comparison of native and introduced (historical and extant) genotypes}

The genetic structure of native, historical non-native, and extant non-native individuals was compared performing Principal Coordinate Analysis (PCOA) on the standardized covariance matrix of pairwise between-individual genotypic distances as calculated in GenAlEx 6.5 (Peakall \& Smouse 2012). Differences in genetic structure between native, historical non-native, and extant non-native individuals were then further examined applying a MANOVA followed by a Tukey LSD Post-hoc comparison on the first ten PCoA axes. The overall distribution of SNP diversity within and among individuals and populations of both native and non-native origin was quantified according to Nei (1973) using GenAlEx 6.5 (Peakall \& Smouse 2012), applying $10^{4}$ permutations to evaluate significance.

This article is protected by copyright. All rights reserved. 
Next, the genetic structure of native, historical non-native, and extant non-native individuals was further explored applying a model-based clustering method using the software STRUCTURE. This Bayesian method clusters individuals as to minimize Hardy-Weinberg disequilibrium and linkage disequilibrium among individuals (Pritchard et al. 2000). Portions of the genome of individuals are then probabilistically assigned to the inferred genetic clusters for a given value of $K$, the optimal number of clusters present in the data. We first applied the admixture model with $10^{5}$ burn-ins, $10^{5}$ repetitions and 15 iterations for each value of $K$, from $K=1$ to 23 , the total number of sampling locations. This identified $\mathrm{K}=2$ as the optimal number of clusters in our data based on second rate order of the evolution of the likelihood of the data $\operatorname{Pr}(X \mid K)$ vs. K (Evanno et al. 2005). We then reran analysis for this optimal value of $\mathrm{K}$ applying $10^{6}$ burn-ins and $10^{6}$ repetitions.

\section{Distribution of SNP diversity within the introduced range}

To explore the spatial distribution of SNP diversity within the introduced range, we applied the same procedure as described above. Here we ran the STRUCTURE admixture model on all extant introduced individuals for $\mathrm{K}=1$ to 12 , the number of extant introduced populations (Fig. S1), identifying $\mathrm{K}=5$ as the most likely number of overall clusters in the introduced range.

Next, to evaluate the genomic signature of spatial expansion, population genetic diversity measures [allele number $\left(\mathrm{N}_{\mathrm{a}}\right)$, and expected heterozygosity $\left(\mathrm{H}_{E}\right.$, Nei 1973)] were calculated using GenAlEx 6.5 (Peakall \& Smouse 2012) and Pearson correlated to a population's distance by water to the putative initial introduction site. These distances were calculated twice using either population $\ln 1$ or population In2 as putative source (both are situated near the historical wool industry area); with QGIS 1.8.0 (Quantum GIS Development Team 2010). All PCoA scores derived from the standardized covariance matrix of mean between-population genotypic distances were entered as dependents into a multivariate General Linear Model with distance by water to $\ln 1$ or $\ln 2$ as a covariate. In addition, Mantel tests were performed correlating interpopulation genetic distances with both

This article is protected by copyright. All rights reserved. 
nearest interpopulation distances along the watercourse and Euclidean interpopulation distances. All statistical analyses were conducted in SPSS Statistics 20 (IBM).

\section{Results}

Comparison of native and introduced (extant and historical) genotypes

Out of the 160 putatively neutral SNPs further analyzed, $95.0 \%$ were polymorphic within the native gene pool ( $n=198$ individuals), 88.7\% were polymorphic within the extant introduced gene pool $(n=188)$ and $91.8 \%$ within the set of historical herbarium specimens collected in the introduced range $(n=47)$. No SNPs were fixed across the set of historical specimens while being polymorphic within the extant introduced gene pool. In further summaries and visual representation, herbarium specimens were split into two equal age groups: collected between 1829 and $1892(n=22)$ and between 1893 and $1955(n=25)$.

PCoA on native, introduced ancient and introduced extant genotypes showed that the vast majority of herbarium specimens collected in the introduced range clearly overlapped with present-day introduced genotypes (Fig. 2). Only the oldest available genotypes, most likely collected before 1860, deviated from this group and were situated in between the genotypes of extant introduced individuals and different native sources. The most divergent genotypes were a specimen collected in 1829 by Alexandre LS Lejeune ( $\left.{ }^{\circ} 1779-1838\right)$, who is alleged the first written record of Pyrenean rocket in Belgium, two undated specimens collected by Barthélemy CJ Dumortier, who surveyed the Vesdre valley together with Lejeune around 1820 (Lawalrée 1980), a specimen collected in 1830 in Verviers and, a specimen collected in 1858 in Nessonveaux (area near In3 in Fig. 1). The collectors of the latter two specimens are unknown. MANOVA-based comparison of individual PCoA scores by the four groups (extant native individuals, extant introduced individual, introduced individuals collected between 1829-1892 and introduced individuals collected between 1892-1955) confirmed significant

This article is protected by copyright. All rights reserved. 
differences in genotypic composition (Wilk's Lambda $\mathrm{F}=101.956, \mathrm{P}<1 \times 10^{-6}$ ). A Tukey HSD post-hoc test suggested significant differences between all groups $(P<0.05)$, except between present-day introduced genotypes and the more recently collected herbarium specimens (1893-1955).

The PCoA further demonstrates that the current introduced gene pool is a homogeneous genetic group relative to the variation present in the native gene pool. The first PCoA axis, which accounted for $19.0 \%$ of the variance, primary discriminated between the extant native and introduced gene pool while the second (Fig. 2) and further axes (not shown) ordered native populations according to their geographic origin. This is also exemplified by the much stronger genetic differentiation among native than among introduced populations (see also Vandepitte et al. 2014). Pairwise $G_{S T}$ values varied between 0.016 and 0.073 in the introduced range (overall $\mathrm{G}_{\mathrm{ST}}=0.063+/-0.004 \mathrm{SE} ; \mathrm{P}<0.0001$ ) while between 0.046 and 0.27 in the native range (overall $G_{S T}=0.260+/-0.012 S E ; P<0.0001$ ). Between-range comparisons ranged from 0.10 to 0.31 . Gene diversity $\left(H_{E \_ \text {native }}=0.22, S E=0.006\right.$; $\left.\mathrm{H}_{\mathrm{E}_{-} \text {introduced }}=0.29, \mathrm{SE}=0.004\right)$ and allele number $\left(\mathrm{N}_{\mathrm{A}_{-} \text {native }}=1.651, \mathrm{SE}=0.018 ; \mathrm{N}_{\mathrm{A}_{-} \text {introduced }}=1.811, \mathrm{SE}=0.009\right)$ were not reduced in extant introduced relative to native populations, indicating there was no lasting genetic bottleneck associated with colonization, as is also supported by the relatively high allelic diversity present in herbarium specimens (Table 1). Inbreeding coefficients $\left(F_{I S}\right)$ averaged 0.054 and did not significantly differ between extant native and introduced populations according to a 2-sample t-test $\left(F_{\text {IS_native }}=0.052, S E=0.014 ; F_{\text {IS_introduced }}=0.056, S E=0.011 ; t=0.216, P=0.831\right)$.

In agreement with the PCOA, STRUCTURE assigned extant native and non-native individuals to two major genetic clusters while several of the oldest herbarium specimens had intermediate genotypes ( $K=2$ in Fig. 3). STRUCTURE runs for higher numbers of $\mathrm{K}$ demonstrated substructuring by geographic location within the native gene pool while extant introduced genotypes were assigned to a single major genetic cluster ( $\mathrm{K}=3$ and $\mathrm{K}=4$ in Fig. 3).

This article is protected by copyright. All rights reserved. 
Extant distribution of genetic variation in the introduced gene pool.

STRUCTURE indicated the presence of five genetic groups in the introduced range ( $K=5$; Fig. 4). Individuals from the known to be relatively recently founded populations downstream the Meuse river ( $\ln 10$ to $\ln 12$ ) displayed admixed genetic profiles with substantial portions of four to all five genetic clusters while individuals from the Meuse population In9 were predominantly assigned to a single distinct cluster. Likewise, most populations located upstream along the Vesdre were assigned to one out of four genetic clusters, prevailing in one or more sampling locations along the Vesdre (but see $\ln 8$ ). In agreement, population $\ln 1, \ln 2, \ln 7$ and $\ln 9$ lied at the four corners of a PCoA plot, while populations located downstream the Vesdre and downstream the Meuse had rather intermediate PCoA scores on the first two axes (Fig. 5), accounting for $22.58 \%$ and $18.15 \%$ of the variance.

Distances along the water course to the most upstream located population In 1 did neither explain the magnitude of within-population genetic diversity nor the spatial distribution of amongpopulation genetic differentiation within the introduced range. Mean within-population genetic diversity parameters $\left(\mathrm{N}_{\mathrm{A}}, \mathrm{N}_{\mathrm{e}}\right.$ and $\mathrm{H}_{\mathrm{E}}$ ) did not decrease with increasing distance from In1 (Fig. 6, Table 1). Furthermore, although STRUCTURE indicated that some nearby populations shared similar genomic profiles (e.g. In10, 11 and 12 in Fig. 4), a multivariate GLM showed no significant effect of distance by water from In 1 on population genetic structure (Wilk's Lambda $F=0.54 ; P=0.79$ ). In accord, Mantel tests rendered no significant overall correlation between distances along the watercourse or Euclidean interpopulation distances and interpopulation mean genotypic distances (both $\mathrm{P}>0.05$ ). Analyses with distances from $\ln 2$ instead of $\ln 1$ were not significant either (not shown).

This article is protected by copyright. All rights reserved. 


\section{Discussion}

Contrasting common expectations regarding the genetic consequences of serial population founding during spatial expansion (e.g. Nei et al. 1975, Le Corre \& Kremer 1998, Slatkin \& Excoffier 2012), no evidence was found for progressive loss of genetic diversity or fixation of alleles with increasing distance from the site of initial colonization, nor did allele frequencies mirror between-population distances along the predominant expansion axis. The magnitude of genetic differentiation among introduced populations was modest but significant (overall $G_{\text {ST_introduced }}=0.063$ vs. $G_{\text {ST_native }}=0.26$ ) and rather patchily than gradually distributed throughout the novel range.

The genetic composition of the historical introduced gene pool suggested no significant influence of additional introductions much after initial establishment, or additional points of entry, on the extant distribution of genetic variation among non-native populations. Given extensive diversity and genetic differentiation within the native gene pool $\left(\mathrm{G}_{\mathrm{ST}}=0.26\right)$, an additionally introduced lineage would most likely appear as a distinct genetic group within the non-native (past) gene pool (Fig. 2). Nonetheless, the genetic composition of almost all individuals collected in the second half of the 19th and early 20th century clearly overlapped with the extant, rather homogeneous, introduced gene pool (Fig. 2), which renders additional introductions after the first half of the $19^{\text {th }}$ century improbable. The extant introduced gene pool thus most likely stems from one main lineage, derived through the admixture of multiple genotypes during the species establishment upstream the Vesdre in the $18^{\text {th }}$ or early 19th century (Fig. 2 and Fig 3). The overall genetic divergence between the native and introduced gene pool may indicate environmental selection (Vandepitte et al. 2014), severe genetic drift following initial introduction and/or admixture with an uncharacterized source; yet, is possibly somewhat inflated by ascertainment bias. The genetic material of approximately equal small numbers of native and introduced individuals was pooled in SNP discovery (Vandepitte et al. 2013), which may have favored SNPs differentiating between the two ranges.

This article is protected by copyright. All rights reserved. 
Historical records of wool import strengthen these inferences. From 1672 onwards, manufacturers in Verviers started to import fine merino wool from Southwest Europe (mainly Spain), which increasingly became indispensable during the 18 th up to the early $19^{\text {th }}$ century because the local wool was too coarse to sustain the high product quality needed for the mounting export (Dechesne 1926, Lebrun 1948). Then, during the 19th century, wool import to Verviers increasingly shifted from import from Southwest Europe to import from overseas (Lebrun 1948) until the collapse of local wool industry in the $20^{\text {th }}$ century, effectively drying up the source of additional introductions from the species' native range.

The maintenance of genetic diversity and the absence of significant spatial genetic structure in the introduced range most probably stems from a non-serial pattern of population founding during expansion. Most theoretical work on the genetic consequences of range expansion thus far assumed diffuse, continuous dispersal patterns (Le Corre \& Kremer 1998, Slatkin \& Excoffier 2012). However, the few available simulation studies on the influence of dispersal modes during spatial expansion indicate that the combination of short distance dispersal with occasional long leaps forward, unless very rare, preserve genetic diversity better than pure diffusion-based dispersal models (Bialozyt et al. 2006, Fayard et al. 2009). In introduced S. austriacum, river dynamics and flooding events likely occasionally transfer propagules over long distances (see Jacquemyn et al. 2006; Jacquemyn et al. 2010), which brings diversity to and ahead of the expansion front, allows recombination of upstream sources (Fig. 4) and so retains gene diversity during spatial expansion (e.g. In 12 in Fig. 6). The presence of modest albeit significant among-population genetic differentiation may then seem counterintuitive yet fits early simulation models by Ibrahim et al. (1996) showing that stratified dispersal, i.e. involving both short and long distance dispersal, can generate a patchy genetic structure by the establishment of 'pocket populations' ahead of the expansion front. In this context, it is perhaps noteworthy that the genetically distinct population $\ln 9$ was sampled in an area along the river Meuse where the species was already abundant by the late 19th century (based on notes written on herbarium material), while $S$. austriacum remained long absent from adjacent places.

This article is protected by copyright. All rights reserved. 
Furthermore, in addition to facilitating occasional long leaps forward, the predominant downstream movement of seeds by water, no longer compensated by additional introductions upstream (see above), may have drained alleles from upstream located populations. This possibly enhanced genetic divergence and the depletion of alleles from upstream located populations (cfr. 'the unidirectional dispersal paradox'; Honnay et al. 2010).

Along with river dynamics, the species' predominant outcrossing mating system, as indicated by the low overall estimate of inbreeding (mean $F_{1 S}=0.05$; Hamrick \& Godt 1996), may have assisted in retaining gene diversity. The maintenance of outcrossing during establishment, as suggested by the comparable degree of homozygosity in extant and historical individuals ( $H_{\mathrm{O}}$ in Table S1), possibly delayed the rapid proliferation of S. austriacum through Allee effects (reduced population growth at low densities). This could have allowed the arrival and intermingling of distinct genotypes and so boosted genetic diversity before the species actually set off along the river course. Likewise, outcrossing may have mitigated the rapid proliferation of (self-pollinating) individuals far ahead of the expansion front and so promoted the maintenance of population genetic diversity throughout spatial expansion (cfr. pushed waves; Hallatschek \& Nelson 2008). Cross-pollination between nearby populations (e.g. In5 and In6; Fig. 1) may also have assisted in restoring the genetic diversity lost through population founding. Nonetheless, the influence of interpopulation pollen exchange is likely limited as most populations, certainly those upstream the Vesdre, are relatively spatially isolated from one another. Finally, the long-time storage of genotypes by means of a persistent seed bank does likely not assist in maintaining genetic diversity in this study system (germination after 4 years of storage at room temperature is $<3 \%$; K. Vandepitte, unpublished data).

The case of S. austriacum hence suggests that spreading introduced species can avert the expected progressive loss of genetic diversity during spatial expansion and maintain high adaptive potential through a discontinuous pattern of dispersal. Several previous investigations, finding no evidence of serial population bottlenecks during the spread of exotic species do exist. Population genetic studies

This article is protected by copyright. All rights reserved. 
of the Japhanese rose (Rosa rugosa) in Europe (Kelager et al. 2013) the South American weed Flaveria bidentis in Northern China (Ma et al. 2011), the Eurasian round Goby (Neogobius melanostomus) in the North-American Great Lakes (Bronnenhuber et al. 2011), and an earlier investigation of Sisymbrium austriacum across a short transect downstream the river Meuse (mean $\Theta_{S T}=0.083$;Jacquemyn et al. 2006, 2010), failed to detect loss of genetic variation during spatial expansiogn. This maintenance of genetic diversity was in all cases attributed to admixture through long-distance gene flow. However, these studies were typically based on less accurate anonymous genetic markers (SSRs, ISSRs or AFLPs), did not rule out the potential influence of complex introduction scenarios nor covered the entire range. In contrast, a recent genome-wide survey of non-native populations of the very slowly dispersing introduced bank vole in Ireland showed a significant reduction in genomic diversity along the species' expansion axis (White et al. 2013), which again underscores the influence of dispersal ability and characteristics on the distribution of genetic diversity in spreading non-native species.

In conclusion, the results of this study deviate from the expectations laid out in the model of serial founding events in population expansion. This is most likely because expansion did not occur as a series of consecutive founding events. As such, it does not provide counter evidence to the serial founding events model (e.g. Le Corre \& Kremer 1998), in which populations expand gradually outward from an initial source, but instead shows that expansion may also occur from multiple dispersal events and admixture from the same founding populations. Along with similar findings in different organisms (e.g. Bronnenhuber et al. 2011, Berthouly-Salazar et al. 2013), this work therefore underscores the need to integrate more complex, discontinuous dispersal modes in simulation and analytical studies on the evolutionary genetic consequences of range expansion as to generate theory apt to more dynamic systems. In the context of biological invasions, our findings in S. austriacum indicate that dispersal of non-native plant propagules by the dynamics of rivers and streams can assist in upholding evolutionary potential during non-native spread, potentially

This article is protected by copyright. All rights reserved. 
stimulating further expansion. Finally, our research highlights the value of a strong historical framework in interpreting extant patterns of genetic diversity in spreading introduced species.

\section{Acknowledgements}

We are grateful to P Breyne for help with sample collection. KV holds a postdoctoral fellowship of the Research Foundation - Flanders (FWO). This research benefitted from the 'KU Leuven programmafinanciering Eco- \& Socio-Evolutionary Dynamics' and from an FWO research grant. We like to thank the anonymous reviewers for their helpful feedback.

\section{Data accessibility}

See http://dx.doi.org/10.5061/dryad.hm74t for the SNP dataset used in this manuscript and Vandepitte et al. (2014) for additional information on SNPs, populations and for the untrimmed genotypes.

\section{References}

Beaumont MA, Nichols RA (1996). Evaluating loci for use in the genetic analysis of population structure. Proc R Soc Lond B 263: 1619-1626.

Berthouly-Salazar C, Hui C, Blackburn T, Gaboriaud C, van Rensburg B, van Vuuren B, Le Roux J (2013) Longdistance dispersal maximizes evolutionary potential during rapid geographic range expansion. Molecular Ecology 22: 5793-5804.

Bialozyt R, Ziegenhagen B, Petit RJ (2006) Contrasting effects of long distance seed dispersal on genetic diversity during range expansion. Journal of Evolutionary Biology 19: 12-20.

Bronnenhuber JE, Dufour BA, Higgs DM, Heath DD (2011) Dispersal strategies, secondary range expansion and invasion genetics of the nonindigenous round goby, Neogobius melanostomus, in Great Lakes tributaries. Molecular Ecology 20: 1845-1859.

Cuppen E (2007) Genotyping by Allele-Specific Amplification (KASPar). Cold Spring Harb Protoc. doi:10.1101/pdb.prot4841.

This article is protected by copyright. All rights reserved. 
Dechesne L (1926) Industrie drapière de la Vesdre avant 1800. J. Wykmans, Liège, MCMXXVI.

Dlugosch KM, Parker IM (2008) Founding events in species invasions: genetic variation, adaptive evolution, and the role of multiple introductions. Molecular Ecology 17: 431-449.

Excoffier L, Foll M, Petit RJ (2009) Genetic Consequences of Range Expansions. Annual Review in Ecology, Evolution, and Systematics 40: 481-501.

Excoffier L, Lischer HEL (2010) Arlequin suite ver 3.5: a new series of programs to perform population genetics analyses under Linux and Windows. Molecular Ecology Resources 10: 564-567.

Evanno G, Regnaut S, Goudet J (2005) Detecting the number of clusters of individuals using the software STRUCTURE: a simulation study. Molecular Ecology 14: 2611-2620.

Fayard J, Klein EK, Lefevre F (2009) Long distance dispersal and the fate of a gene from the colonization front. Journal of Evolutionary Biology 22: 2171.

Hallatschek O, Nelson DR (2008) Gene surfing in expanding populations. Theoretical Population Biology 73 : 158-170.

Honnay O, Jacquemyn H, Breyne P, Nackaerts K, Van Looy K (2010). Patterns of population genetic diversity in riparian and aquatic plant species along rivers. Journal of Biogeography 37: 1730-1739

Ibrahim KM, Nichols RA, Hewitt GM (1996) Spatial patterns of genetic variation generated by different forms of dispersal during range expansion. Heredity 77:282-291.

Jacquemyn H, Honnay O, Van Looy K, Breyne P (2006). Spatiotemporal structure of genetic variation of a spreading plant metapopulation on dynamic riverbanks along the Meuse River. Heredity 96: 471-478.

Jacquemyn H, Van Looy K, Breyne P, Honnay O (2010) The Meuse river as a corridor for range expansion of the exotic plant species Sisymbrium austriacum: evidence for long-distance seed dispersal. Biological Invasions 12: 553-561.

Kelager A, Pedersen JS, Bruun HH (2013) Multiple introductions and no loss of genetic diversity: invasion history of Japanese Rose, Rosa rugosa, in Europe. Biological Invasions 15: 1125-1141.

Lachmuth S, Durka W, Schurr FM (2010) The making of a rapid plant invader: genetic diversity and differentiation in the native and invaded range of Senecio inaequidens. Molecular Ecology 19: 3952-3967.

Lawalrée A (1980) "Barthélemy Dumortier 1797-1878", in Florilège des Sciences en Belgique, vol. II, p. 545-546.

Lebrun P (1948) L'industrie de la laine à Verviers pendant le XVIIlè et le début du XIXè siècle. Contribution à l'étude des origines de la révolution industrielle. Faculté de Philosophie et Lettres, Liège.

Le Corre V, Kremer A (1998) Cumulative effects of founding events during colonisation on genetic diversity and differentiation in an island and stepping-stone model. Journal of Evolutionary Biology 11: 495-512.

Ma JW, Geng SL, Wang SB, et al. (2011) Genetic diversity of the newly invasive weed Flaveria bidentis (Asteraceae) reveals consequences of its rapid range expansion in northern China. Weed Research 51: 363-372.

Möst M, Oexle S, Marková S, Aidukaite D, Baumgartner L, Stich HB, Wessels M, Martin-Creuzburg D, Spaak P (2015) Population genetic dynamics of an invasion reconstructed from the sediment egg bank. Molecular Ecology, 24: 4074-4093.

This article is protected by copyright. All rights reserved. 
Nei M (1973) Analysis of gene diversity in subdivided populations. Proceedings of the National Academy of Sciences 70: 3321-3323.

Nei M, Maruyama T, Chakraborty R (1975) The bottleneck effect and genetic variability in populations. Evolution 29:1-10.

Peakall R, Smouse PE (2012) GenAIEx 6.5: genetic analysis in Excel. Population genetic software for teaching and research-an update. Bioinformatics 28: 2537-2539.

Peischl S, Dupanloup I, Kirkpatrick M \& Excoffier L (2013) On the accumulation of deleterious mutations during range expansions. Molecular Ecology 22: 5972-5982.

Peischl S \& Excoffier L (2015) Expansion load: recessive mutations and the role of standing genetic variation. Molecular Ecology 24: 2084-2094.

Pritchard JK, Stephens M, Donnelly P (2000) Inference of population structure using multilocus genotype data. Genetics 155: 945-959.

Rosenthal DM, Ramakrishnan A, Cruzan MB (2008) Evidence for multiple sources of invasion and intraspecific hybridization in Brachypodium sylvaticum (Hudson) Beauv. in North America. Molecular Ecology, 17, 46574669.

Slatkin M, Excoffier L (2012) Serial Founder Effects During Range Expansion: A Spatial Analog of Genetic Drift. Genetics 191: 171-181.

Tutin, TG (1983) Flora Europaea: Psilotaceae to Plantaceae (Cambridge University Press, Cambridge) 1, 325 pp.

Vandepitte K, Honnay O, Mergeay J, et al. (2013) SNP discovery using Paired-End RAD-tag sequencing on pooled genomic DNA of Sisymbrium austriacum (Brassicaceae). Molecular Ecology Resources 13: 269-275.

Vandepitte, K., De Meyer, T., Helsen, K., Van Acker, K., Roldan-Ruiz, I., Mergeay, J., Honnay, O. (2014) Rapid genetic adaptation precedes the spread of an exotic plant species. Molecular Ecology 23: 2157-2164.

Van Landuyt, W., Hoste, I., Vanhecke, L., Van Den Bremt, P., Vercruysse, W., de Beer, D. (2006) Atlas van de flora van Vlaanderen en het Brussels Gewest. Flo.Wer/Instituut voor Natuur- en Bosonderzoek/Nationale Plantentuin van België: Brussel. ISBN 90-726-1968-4. 1007 pp.

White TA, Perkins SE, Heckel G, Searle JB (2013) Adaptive evolution during an ongoing range expansion: the invasive bank vole (Myodes glareolus) in Ireland. Molecular Ecology 22: 2971-2985.

\section{Figure legends}

Fig 1. Map of the extant sampled populations across the native and introduced range of Sisymbrium austriacum (adapted from Vandepitte et al. 2014). In the introduced range, the tributary Vesdre and main river Meuse flow from $\ln 1$ to $\ln 12$.

Fig 2. Principal Coordinates Analysis (PCoA) plot based on the individual scores of native (grey symbol), historical introduced (red and green) and extant introduced (blue) Sisymbrium austriacum genotypes. For visual representation, herbarium specimens were assigned to two age classes: collected before (red) and after (green) 1892.

This article is protected by copyright. All rights reserved. 
Fig 3. StRUCTURE barplot of individual assignment results of all native, historical non-native, and extant non-native Sisymbrium austriacum individuals for $\mathrm{K}=2$ to 4 . The method of Evanno et al. (2005) indicated $\mathrm{K}=2$ as the most likely number of major clusters. The two leftmost groups are nonnative herbarium specimens collected before (1) and after (2) 1892. Numbers 3 to 14 in the graph represent individuals from introduced populations ( $\ln 1$ to $\ln 12$ in consecutive order); number 15 to 25 the eleven sampled native populations ( $\mathrm{Na} 1$ to $\mathrm{Na} 11$ ). From $\mathrm{K}=5$ on, results were inconsistent among iterations and are therefore not displayed.

Fig. 4. STRUCTURE barplot of individual assignment results for $\mathrm{K}=5$, of extant non-native Sisymbrium austriacum populations. Individuals are sorted from the left to the right by sampling location along the river course. Numbers correspond to the population codes In_ in Fig. 1.

Fig. 5. Principal Coordinates Analysis (PCOA) plot based on mean genotypic distances between extant introduced populations only.

Fig 6. Population genetic diversity (gene diversity, $\mathrm{H}_{\mathrm{E}}$ ) versus distance by water to the introduction site (approximated as $\ln 1$ ). Error bars represent the standard error.

Table 1. Mean population genetic parameters of $S$. austriacum based on 160 SNPs as calculated in GenAIEx 6.5 (Peakall \& Smouse 2012).

\begin{tabular}{|c|c|c|c|c|c|c|c|c|c|}
\hline PopID & $\mathrm{n}$ & $\mathbf{N}_{\mathrm{A}}$ & $\operatorname{SE}\left(N_{A}\right)$ & Ho & $\mathrm{SE}(\mathrm{Ho})$ & $\mathrm{He}$ & $\mathrm{SE}(\mathrm{He})$ & $F_{1 S}$ & $\operatorname{SE}\left(F_{1 S}\right)$ \\
\hline Herb $_{1829-1992}$ & 22 & 1.888 & 0.025 & 0.244 & 0.014 & NA & NA & NA & NA \\
\hline Herb $_{1893-1955}$ & 25 & 1.900 & 0.024 & 0.271 & 0.015 & NA & NA & NA & NA \\
\hline $\ln 1$ & 30 & 1.825 & 0.030 & 0.250 & 0.016 & 0.285 & 0.015 & 0.121 & 0.027 \\
\hline $\ln 2$ & $11^{*}$ & 1.781 & 0.033 & 0.261 & 0.018 & 0.280 & 0.015 & 0.064 & 0.033 \\
\hline $\ln 3$ & 19 & 1.838 & 0.029 & 0.285 & 0.017 & 0.300 & 0.014 & 0.071 & 0.029 \\
\hline $\ln 4$ & 18 & 1.856 & 0.028 & 0.292 & 0.017 & 0.307 & 0.014 & 0.062 & 0.029 \\
\hline $\ln 5$ & $12 *$ & 1.813 & 0.031 & 0.289 & 0.019 & 0.295 & 0.014 & 0.024 & 0.033 \\
\hline $\ln 6$ & $11 *$ & 1.788 & 0.032 & 0.290 & 0.020 & 0.291 & 0.015 & 0.020 & 0.033 \\
\hline $\ln 7$ & $16^{*}$ & 1.788 & 0.032 & 0.258 & 0.017 & 0.271 & 0.015 & 0.047 & 0.027 \\
\hline $\ln 8$ & $15^{*}$ & 1.825 & 0.030 & 0.279 & 0.018 & 0.308 & 0.014 & 0.105 & 0.032 \\
\hline $\ln 9$ & $17^{*}$ & 1.781 & 0.033 & 0.275 & 0.019 & 0.276 & 0.015 & 0.030 & 0.032 \\
\hline $\ln 10$ & $7^{*}$ & 1.769 & 0.033 & 0.275 & 0.019 & 0.274 & 0.015 & -0.005 & 0.035 \\
\hline $\ln 11$ & $10 *$ & 1.806 & 0.031 & 0.283 & 0.018 & 0.293 & 0.015 & 0.026 & 0.028 \\
\hline $\ln 12$ & 22 & 1.869 & 0.027 & 0.295 & 0.017 & 0.324 & 0.014 & 0.100 & 0.031 \\
\hline
\end{tabular}

This article is protected by copyright. All rights reserved. 


\begin{tabular}{|c|c|c|c|c|c|c|c|c|c|}
\hline Na1 & $14^{*}$ & 1.588 & 0.039 & 0.196 & 0.018 & 0.205 & 0.016 & 0.048 & 0.034 \\
\hline $\mathrm{Na} 2$ & 19 & 1.681 & 0.037 & 0.213 & 0.018 & 0.218 & 0.015 & 0.032 & 0.029 \\
\hline $\mathrm{Na} 3$ & 20 & 1.613 & 0.039 & 0.202 & 0.019 & 0.206 & 0.016 & 0.049 & 0.031 \\
\hline Na4 & 20 & 1.719 & 0.036 & 0.242 & 0.018 & 0.239 & 0.015 & -0.002 & 0.026 \\
\hline $\mathrm{Na} 5$ & 18 & 1.563 & 0.039 & 0.208 & 0.019 & 0.195 & 0.016 & -0.040 & 0.028 \\
\hline $\mathrm{Na} 6$ & 20 & 1.600 & 0.039 & 0.196 & 0.018 & 0.212 & 0.016 & 0.072 & 0.030 \\
\hline $\mathrm{Na7}$ & $14 *$ & 1.606 & 0.039 & 0.214 & 0.019 & 0.221 & 0.017 & 0.052 & 0.031 \\
\hline $\mathrm{Na} 8$ & $15^{*}$ & 1.694 & 0.037 & 0.200 & 0.016 & 0.229 & 0.016 & 0.131 & 0.029 \\
\hline $\mathrm{Na9}$ & 20 & 1.738 & 0.035 & 0.210 & 0.016 & 0.226 & 0.015 & 0.063 & 0.024 \\
\hline $\mathrm{Na10}$ & 19 & 1.650 & 0.038 & 0.208 & 0.018 & 0.225 & 0.016 & 0.089 & 0.031 \\
\hline $\mathrm{Na11}$ & 19 & 1.713 & 0.036 & 0.214 & 0.016 & 0.224 & 0.015 & 0.074 & 0.027 \\
\hline
\end{tabular}

$\mathrm{n}=$ number of individuals genotyped, $\mathrm{N}_{\mathrm{A}}=$ number of alleles, $\mathrm{Ho}=$ observed heterozygosity, $\mathrm{He}=$ expected heterozygosity, $\mathrm{F}_{\mathrm{IS}}=$ inbreeding coefficient, $\mathrm{SE}=$ standard error. *: all individuals present at this location were sampled.

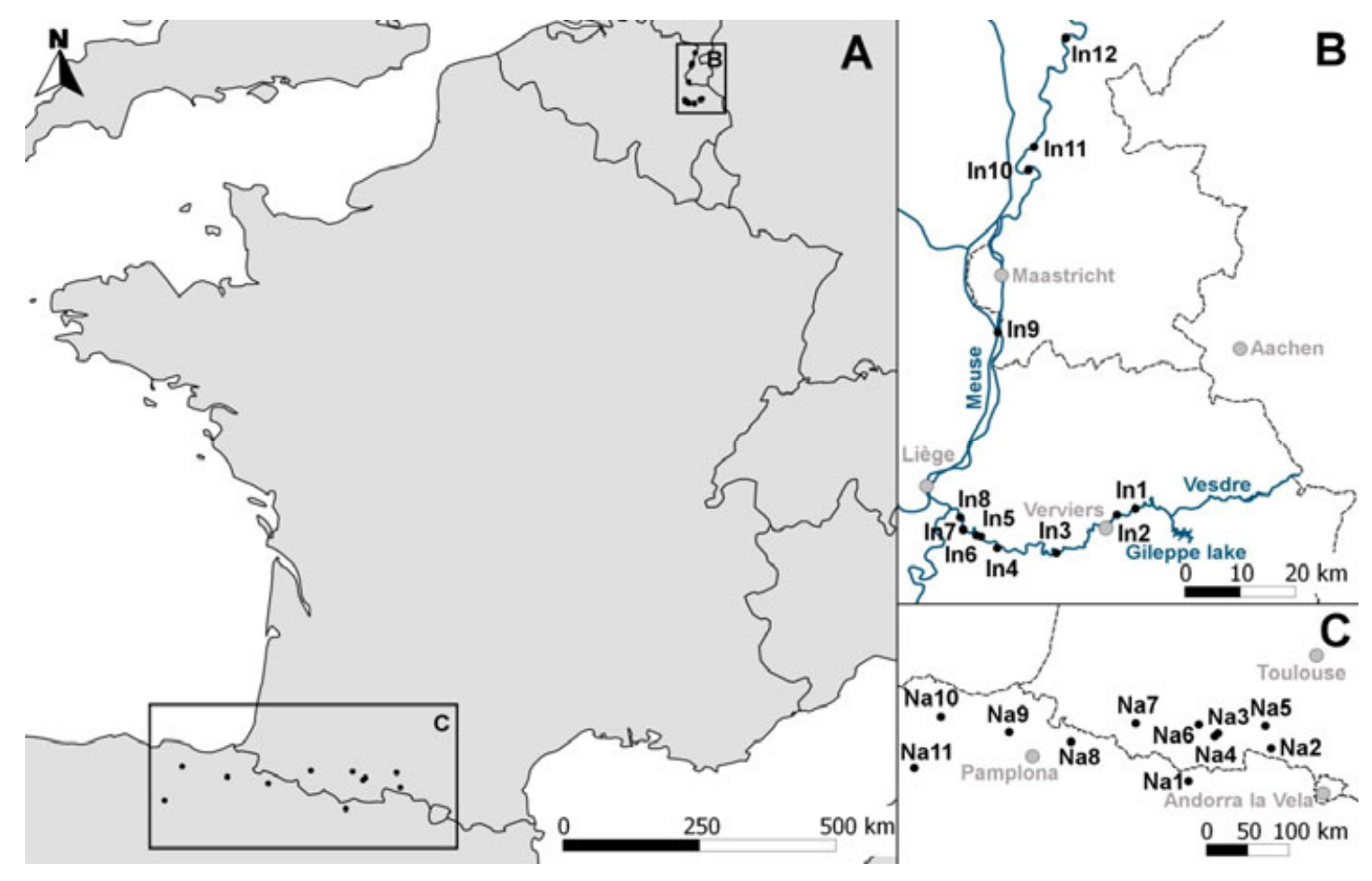

This article is protected by copyright. All rights reserved. 


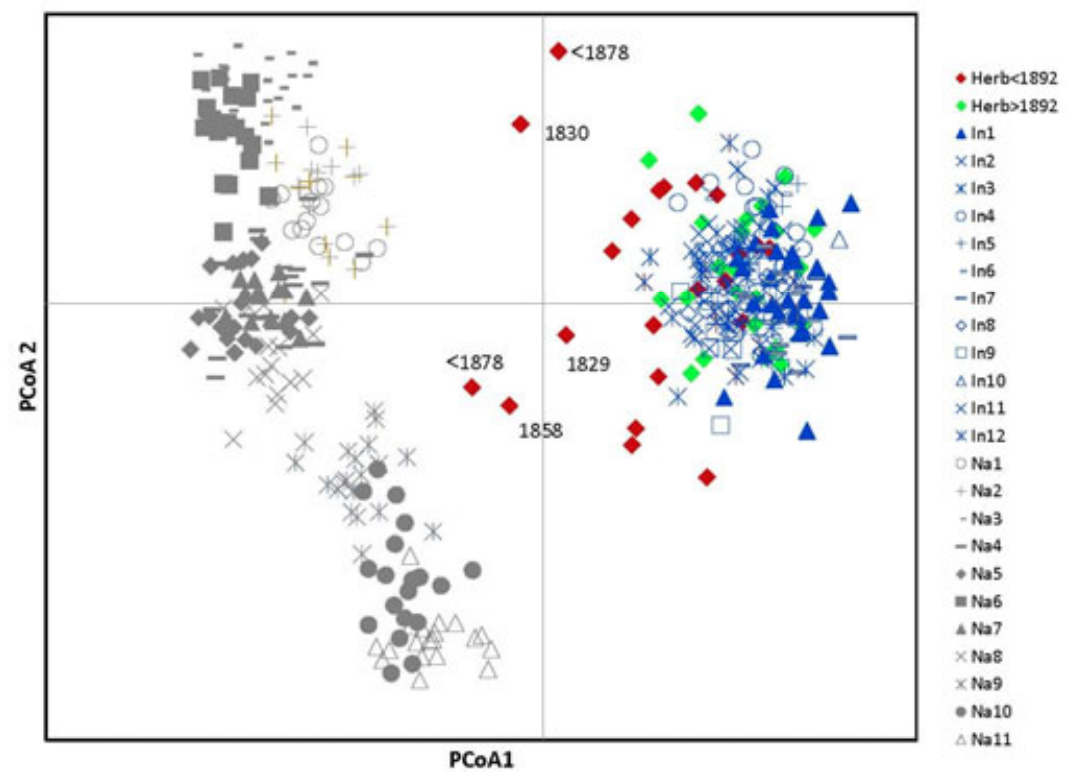

This article is protected by copyright. All rights reserved. 

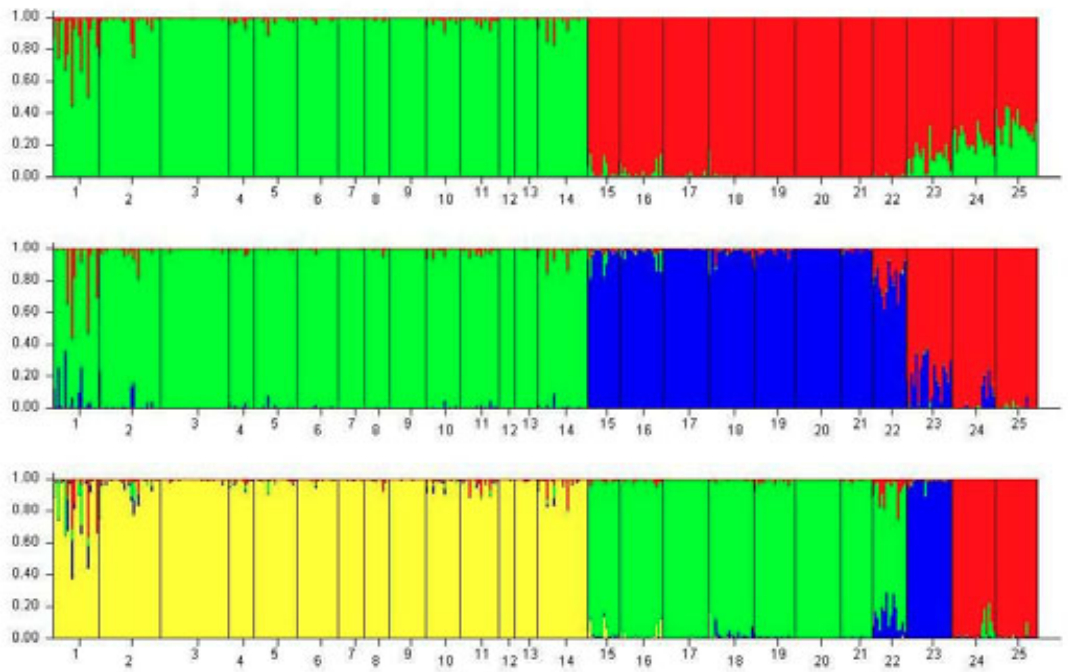

This article is protected by copyright. All rights reserved. 

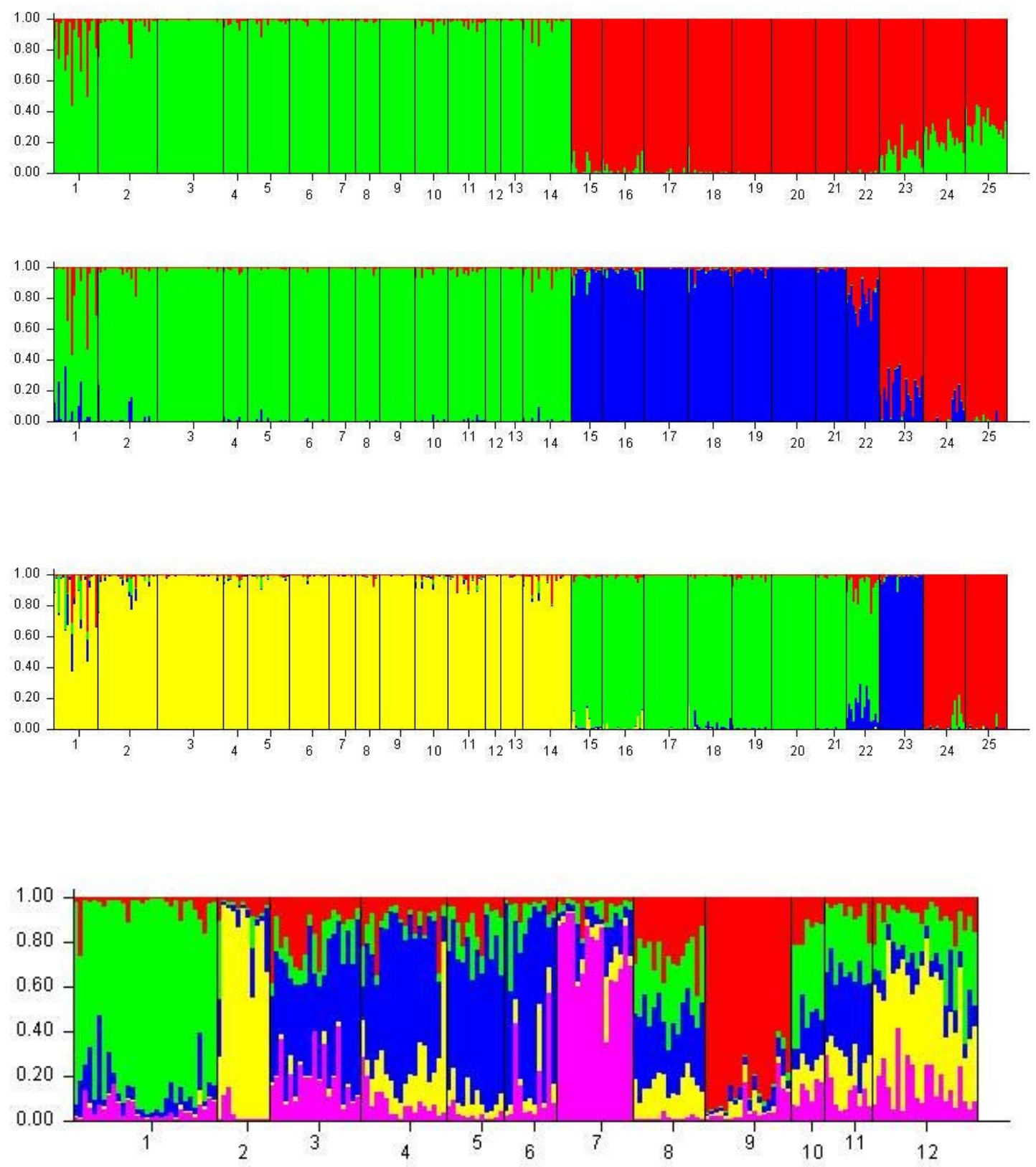

This article is protected by copyright. All rights reserved. 

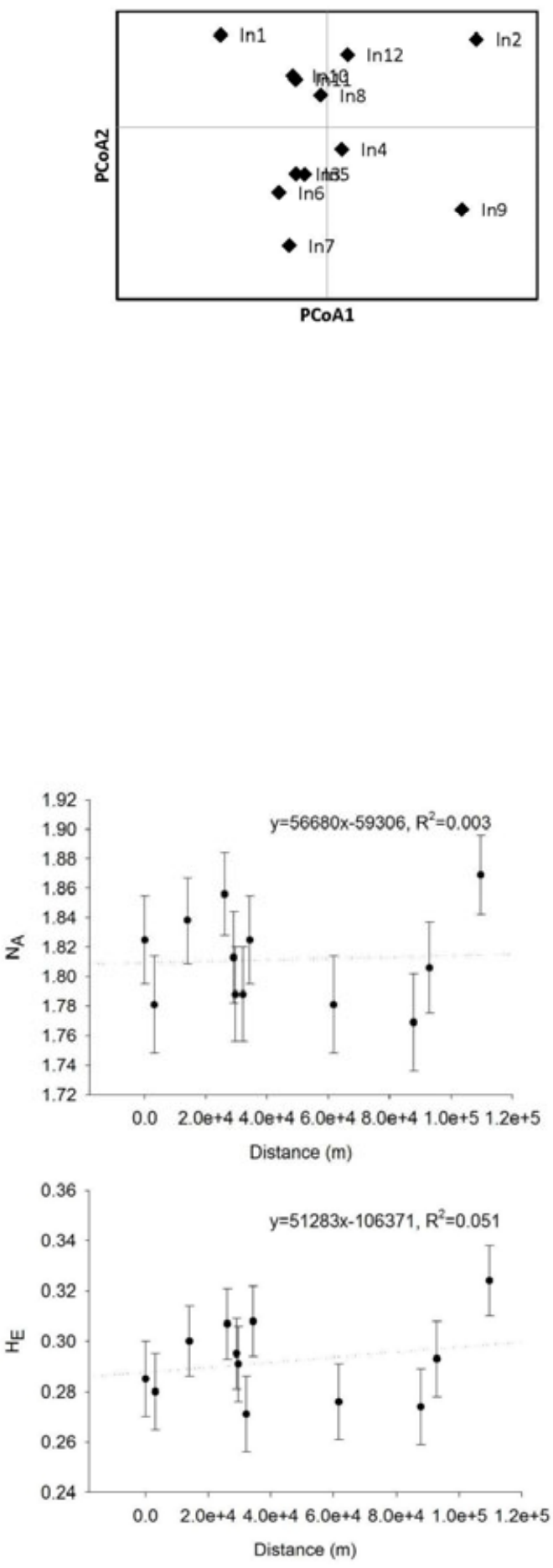

This article is protected by copyright. All rights reserved. 